\title{
VIII
}

\section{HISTÓRIA DA ÁFRICA E DO NEGRO NO BRASIL: REFLEXÕES SOBRE O MATERIAL "TRILHAS DE APRENDIZAGENS”*}

\author{
Allan Alves de Santana ${ }^{1}$ \\ Grazielly Alves Pereira ${ }^{2}$ \\ Irana de Oliveira Mariano ${ }^{3}$ \\ Patrícia Cerqueira dos Santos ${ }^{4}$
}

\section{Introdução}

O que um profissional da educação deve ter em mente ao produzir um material didático de amplo alcance, como um livro didático, ou material semelhante? Em linhas gerais, deve-se observar os referenciais curriculares (em diferentes âmbitos), considerar o debate teórico relacionado à educação, tal como, considerar o debate teórico das áreas que serão trabalhadas no material a ser produzido, além de acompanhar as demandas sociais, de modo a não desenvolver um artefato pedagógico completamente descolado da realidade concreta dos maiores interessados no material: os discentes.

Isso significa que a produção de qualquer material desta natureza requer cuidado e um trabalho de revisão bibliográfica, tal como, de revisão da legislação vigente e demais documentos orientadores. É necessário também considerar estabelecer diálogos com os especialistas na área a ser trabalhada, e com os agentes sociais que farão uso do material. Porém, é possível seguir este conjunto de pressupostos quando se vive um contexto de emergência de saúde pú-

\footnotetext{
*DOI- 10.29388/978-65-86678-50-5-0-f.171-190

${ }^{1}$ Professor da prefeitura do município de São Paulo - Mestre em ensino de História pela Universidade Federal de São Paulo - UNIFESP.

${ }^{2}$ Professora da prefeitura do município de São Paulo - Mestra em ensino de História pela Universidade Federal de São Paulo - UNIFESP.

${ }^{3}$ Professora da prefeitura do município de São Paulo - Mestra em História da Ciência pela Pontifícia Universidade Católica de São Paulo - PUC-SP.

${ }^{4}$ Professora da prefeitura do município de São Paulo - Mestra em História Social pela Pontifícia Universidade Católica de São Paulo - PUC-SP.
} 
blica, tal qual, o que temos vivido com a pandemia de COVID-19? ${ }^{5}$ É possível produzir um material como parte de um plano de ações que visa garantir um mínimo de condições para promover situações de ensino e aprendizagem, de forma responsável e relevante? E quando o assunto diz respeito ao trato de questões que já são problematizadas com dificuldade, mesmo por especialistas que dedicam suas carreiras ao tema, como é o caso com o ensino de História da África e do negro no Brasil? Uma equipe de trabalho em uma gestão municipal poderia produzir um caderno de exercícios na área de Ciências Humanas ${ }^{6}$, tratando de temas sensíveis como os citados, de forma responsável e relevante, em meio ao contexto de pandemia em questão?

As autoras e o autor deste texto entendem que a resposta para estas questões é: sim, tais tarefas são realizáveis. No entanto, qual a qualidade do material Trilhas de aprendizagens, com o qual discentes e professores tiveram que trabalhar, no que concerne ao estudo da História da África e do negro no Brasil? Esse será o questionamento que nos moverá neste estudo.

A questão que se coloca não é a qualidade da equipe que elaborou o material - que acreditamos ser competente. A questão que colocamos é a falta de membros especializados no assunto quando falamos de História da África e do negro no Brasil (assim como das questões indígenas, LGBTQIA+, mulheres, etc.).

Quando mencionamos membros, nos referimos a um grupo que além de ter pessoas especializadas de diferentes vivências e opiniões, também deve abranger, em igual ou maior número, especialistas que vivenciam cotidianamente aquilo que se dispõem a analisar e, que como participantes de um grupo social, devem ter seu lugar de fala ${ }^{7}$ garantido.

Entre os anos de 2015 e 2016, vivenciamos ${ }^{8}$ os Grupos de Trabalho voltados às questões étnico-raciais das Diretorias Regionais de Ensino Freguesia do Ó/Brasilândia (GT Étnico-racial DRE FÓ/BRAS) e Campo Limpo (GT Étnico-racial DRE CL). Os grupos contavam com professores de diversas escolas e ciclos de aprendizagens, tendo sido um período de profícua discussão sobre o tema. Isso porque o grupo era formado por pessoas de diferentes grupos sociais, mas, se levava em consideração a fala, vivência e estudo do negro e

\footnotetext{
${ }^{5}$ Salientamos que o texto foi escrito no segundo semestre de 2020.

${ }^{6}$ Lembrando que no caso da rede estudada, História e Geografia são disciplinas autônomas. No entanto, na ocasião da proposição das Trilhas de aprendizagens, elas foram colocadas juntas na mesma unidade, como se fossem a mesma coisa.

${ }^{7}$ Sobre "lugar de fala" ver: RIBEIRO, 2017.

${ }^{8}$ Nos referimos à participação das autoras Irana de Oliveira Mariano e Patrícia Santos em grupos dessa natureza.
} 
do indígena, questões para as quais o GT se debruçou tendo em vista a Lei ${ }^{\circ}$ 11.645 (BRASIL, 2008). Muitas vezes esses professores foram consultados, demonstrando que o GT era um local onde se problematizavam as questões e, que seguindo um método, procurava resolvê-las.

Provavelmente, se esse GT ainda existisse nos moldes e objetivos para os quais fora formado, não observaríamos, nas Trilhas de aprendizagens, algumas atividades pouco favoráveis ao negro.

Nesse sentido, propomos submeter o material Trilhas de aprendizagens a um exame à luz do debate teórico sobre o ensino de História da África e do negro no Brasil, problematizando a natureza de seus exercícios, a articulação das fontes, seus objetivos e as representações construídas. Temos como objetivo verificar as possibilidades e desafios em trabalhar com este material. A ideia é apontar caminhos e checar os limites do material, proporcionando ao leitor um painel que inspire uma atuação pedagógica crítica e atenta à mobilização responsável de conteúdos relacionados à História da África e do negro no Brasil.

\section{Análise das atividades "Autorretratos" e "Fazendo meu autorretrato"}

Iniciaremos a discussão analisando as atividades sobre autorretratos presentes na parte de Ciências Humanas do livro Trilhas de Aprendizagens (SÃO PAULO, 2020a), do $5^{\circ}$ ano do Ensino Fundamental I (Ciclo interdisciplinar), a saber: "Atividade 1 - Autorretratos", páginas 118-119 e "Atividade 2 - Fazendo meu autorretrato", páginas 119-122.

A "Atividade 1 - Autorretratos" inicia com a pergunta "Você sabe o que é um autorretrato?" Apresenta através de imagens os autorretratos de Van Gogh (1853-1890) e Almeida Júnior (1850-1899) e um quadro de destaque contendo um pequeno texto sobre Rembrandt Harmenszoon van Rijn (1606-1669). O exercício tem três itens dos quais dois são sobre observações voltadas para as questões artísticas das pinturas de Van Gogh e Almeida Júnior e uma sobre o destaque que o discente daria ao seu autorretrato.

A "Atividade 2 - Fazendo meu autorretrato" conta com sete itens: três que solicitam desenhos e quatro dissertativos que analisam as características, semelhanças e diferenças dos/ entre os desenhos. A atividade encerra com a frase: "Vimos que há diferenças entre como nos percebemos e como os outros nos veem. Marcas de nossa identidade e nossa diversidade." 
Em função das aulas remotas em tempos de pandemia, há pontos positivos nas atividades, como a possibilidade de serem feitas sem o auxílio de terceiros $^{9}$, afinal sabemos que há crianças que têm responsáveis que não aprenderam, ou não se apropriaram, da leitura e da escrita e que por isso, em suas residências, não contam com auxílio para o estudo.

A “Atividade 1" também apresenta a variedade de três pintores, um deles, brasileiro. Em ambas atividades destacam-se a leitura de imagens dialogando com as questões solicitadas por escrito e a participação do discente com suas análises, desenhos, interação e apreciação do trabalho do outro em diálogo com o seu.

Sabemos que as atividades de História que envolvem a produção de autorretratos geralmente trabalham questões referentes à construção e percepção do "eu". Ao docente a atividade permite a abordagem da desigualdade, a valorização da diversidade e mostra parte do que o discente pensa sobre si e os objetivos que tem para consigo.

Através do autorretrato podemos perceber como o discente se vê, parte de sua autoconfiança e autoestima, ou ausências delas. É uma atividade que permite a autoexpressão, autorrepresentação; (re/des)construção, alteração e afirmação de identidade e; a individualidade que se estende ao grupo. Todas es sas questões que vão além da imagem e que necessitam da observação e sensibilidade ao olhar para si e para o outro (AMARAL, 2018. RAUEN e MOMOLI, 2015).

Assim, essa é uma atividade que prioriza a observação. No caso das atividades oferecidas no material Trilhas de Aprendizagens (SÃO PAULO, 2020a), essa observação consta somente com os autorretratos e biografia de três artistas homens e brancos em uma atividade oferecida a um grupo de discentes de vários grupos étnico-raciais, identidades e expressões de gênero.

Não somos contra a imagem do homem branco na atividade e sim a favor da oferta de outras possibilidades além desta, tendo em vista que as pessoas são diferentes, constituem grupos diversos e que essas atividades estão privilegiando um grupo determinado cuja conhecida imagem sempre é divulgada e privilegiada na sociedade.

São três artistas que aparecem nas atividades, assim cada uma das duas imagens poderia apresentar artistas da etnia negra e indígena de identidade e expressões de gêneros diferentes. Ressaltamos que o lugar para ambos artistas seriam os das imagens, com o objetivo de apresentar uma perspectiva que geral-

${ }^{9}$ Como previsto em: CAETANO, Bruno. Queridos Estudantes. In: SÃO PAULO, 2020a. 
mente não é feita no livro didático ou na sociedade, que normalmente representam o negro e o indígena de uma forma estereotipada.

Essa proposta permitiria: (1) o negro e o indígena como protagonistas e seres dignos de terem suas obras de arte contempladas para apreciação e análise; (2) a aplicação da Lei no 11.645 (BRASIL, 2008) que tornou obrigatório o estudo da história e cultura afro-brasileira e indígena nos estabelecimentos de ensino fundamental e de ensino médio; (3) apresentar diferentes identidades e expressões de gênero, possibilitando uma reflexão sobre a necessidade de se respeitar a diversidade da sexualidade humana; (4) fazer jus ao documento Currículo da cidade: História (SÃO PAULO, 2019, p. 81, 84-85) que, dentre outras coisas, prevê para o $5^{\circ}$ ano o estudo de povos indígenas e negros; (5) demonstrar a equidade prevista no Currículo da cidade: História (SÃO PAULO, 2019) e nas Orientacõoes didáticas do currículo da cidade: História (SÃO PAULO, 2019); (6) contemplar a educação antirracista e a diversidade cultural prevista no item "5 ${ }^{\circ}$ ano - Quem somos: construção de identidades sociais e culturais e comparações" prevista no Caderno de Orientações Didáticas - Educação Etnicorracial - Ciclo I (SÃO PAULO, 2010, p. 88); (7) o autorreconhecimento e autovalorização de alguns discentes com características constantemente desprezadas pela sociedade.

Na perspectiva da apresentação de um artista negro, que nos cabe neste capítulo, a possibilidade de escolha de nomes para tal é abrangente: Archibald John Motley Jr. (1891-1981), Antônio Rafael Pinto Bandeira (1863-1896), Arthur Bispo do Rosário (1909/11?-1989), Arthur Timótheo da Costa (18821922), Benedito José de Andrade (1906-1979), Benedito José Tobias (18941963), Emmanuel Zamor (1840-1917), Estevão Silva (1845-1891), Firmino Monteiro (1855-1888), Horácio Hora (1853-1890), João Timótheo (1879-1932), Jean-Michel Basquiat (1960-1988), Juliana dos Santos (1987), Loïs Mailou Jones (1905-1998), Maria Auxiliadora da Silva (1935-1974), Maxwell Alexandre (1990), Mickalene Thomas (1971), Renata Felinto (1978), Rosana Paulino (1967), Whitfield Lovell (1959), Wilson Tibério (1923-2005) etc. Logo, artistas não nos faltam, e parte destes têm o autorretrato divulgado na Internet.

Quando afirmamos que o autorretrato de um artista negro em um livro didático poderia colocar o negro como protagonista e ser digno de ter sua obra de arte contemplada para apreciação e análise, fazemos referência a uma forma de transmitir uma mensagem aos discentes através da imagem tornando o negro sujeito ativo de igual competência na construção da história, diferindo da imagem apresentada no livro Trilhas de aprendiragens (SÃO PAULO, 2020a), página 128, "Atividade 5 - Leitura de imagem", no qual as mulheres negras são apre- 
sentadas lutando contra a Ciência na Revolta da Vacina. Talvez justifique-se que também há brancos fazendo o mesmo, mas vemos na imagem, que do lado oposto, há somente pessoas brancas lutando pela Ciência e esquecemos que nessa época um dos maiores defensores do higienismo e do sanitarismo, era o médico negro, mundialmente reconhecido, Juliano Moreira (1873-1933)(MOREIRA, s.d.). Daí, podemos perceber as escolhas feitas através das atividades para representação de um grupo étnico-racial.

Sabemos que a imagem transmite uma mensagem e por isso, concluímos que as imagens oferecidas em Ciências Humanas nas Trilhas de aprendizagens (SÃO PAULO, 2020a) não contemplam satisfatoriamente os seguintes itens: população negra como agente de sua história; equidade prevista no Currículo da cidade: História (SÃO PAULO, 2019) e nas Orientações didáticas do currículo da cidade: História (SÃO PAULO, 2019); educação antirracista e diversidade cultural previstas no Caderno de Orientações Didáticas - Educação Etnicorracial - Ciclo I (SÃO PAULO, 2010) e; cumprimento da Lei $n^{\circ} 10.639$ (BRASIL, 2003), alterada pela Lei $\mathrm{n}^{\circ} 11.645$ (BRASIL, 2008).

\section{Análise da atividade “África: berço das civilizações”}

Dando sequência ao que se dispõe este artigo, nas linhas a seguir, desenvolveremos a análise da atividade 4 em Ciências Humanas, das Trilhas de aprendizagens para o $6^{\circ}$ ano, intitulada “África: berço das civilizações". De saída, podemos imaginar que a atividade garantirá o devido espaço de protagonismo aos povos africanos na discussão sobre o início da Antiguidade. A ideia é propor um estudo de três civilizações africanas que marcaram esse contexto histórico: a civilização cuxita, axumita e egípcia. Tentemos compreender, portanto, quais são as trilhas que a atividade propõe para educadores e educandos.

Como elemento disparador, a atividade traz como primeiro texto o seguinte: "Quais imagens que temos em mente quando nos referimos ao continente africano? Como são os povos que lá vivem ou viveram? Quais tecnologias desenvolveram?" Questões elementares para o início da conversa. O texto segue: "Muito do que conhecemos da África chega até nós pelos meios de comunicação de massa. Filmes como os de Tarzan e outros popularizados pelo cinema e TV trazem para nós visões distorcidas do povo africano, de suas tradições e sabedoria.” (SÃO PAULO, 2020b, p. 122). As interrogações e as afirmações problematizam de forma sucinta as representações que os estudantes podem ter, levando em consideração o seu cabedal de conhecimento, que fora do 
ambiente escolar, se constrói de maneira significativa através de mídias audiovisuais. O texto acerta em apontar que muito do que se sabe, dessa forma, pode estar errado ou distorcido. Assim, o leitor supõe que a atividade oferecerá uma abordagem diferente em relação à História da África.

Até aqui, a atividade atende aos pressupostos normativos da Lei Federal 10.639/03, tal como, das Diretrizes para a educação das relações étnico-raciais de 2004. A atividade promete abordar a História dos povos africanos rompendo com visões estereotipadas. Assim, parecem seguir na trilha do que o movimento negro brasileiro reivindica pelo menos desde a década de 1940: uma mudança nos mapas culturais (GONÇALVES e SILVA, 2000, p. 149).

A atividade adota um caminho usual entre professores: apresenta-se um texto, acompanhado de imagens, que serão lidos e articulados para responder alguma questão.

Os primeiros dois textos apresentados tratam do Egito Antigo. O primeiro é um trecho do livro Para entender o negro no Brasil hoje, do antropólogo Kabengele Munanga. O segundo, um trecho da coleção História geral da África (volume 2), escrito pelo historiador Cheik Anta Diop. Os propositores da atividade buscaram duas referências sólidas dos estudos históricos africanos. Os textos tratam da questão étnica quanto ao Egito Antigo. Ambos provocam e apontam para o fato de que os antigos egípcios eram negros, contrariando o que muitas vezes é exibido em filmes, séries, telenovelas, ou desenhos animados. Até aqui, a atividade segue contundente e firme nos propósitos iniciais apresentados. Na sequência das sete linhas de textos dedicadas ao Egito Antigo, estão dispostas seis imagens que ilustram aspectos da cultura desta civilização: observamos pirâmides, esfinges, estátuas e hieróglifos. Fica nítida a grandeza do Egito Antigo como uma referência na arquitetura, no desenvolvimento de técnicas de escrita, na manipulação de metais e na produção de arte. Todavia, nenhuma das imagens dialoga diretamente com a problematização dos dois textos sobre a civilização: nenhuma delas discute diretamente a composição étnica do Egito Antigo.

Após quase duas páginas dedicadas ao Egito, temos um texto que aborda a civilização cuxita. Em menos de duas linhas, mais uma citação de Kabengele Munanga: "Uma das características da civilização cuxita é o reinado feminino que contou com várias linhagens das rainhas-mães, as Candances" (MUNANGA, 2004, apud: SÃO PAULO, 2020b, p. 124) ${ }^{10}$. O fenômeno do

\footnotetext{
${ }^{10}$ Sobre o termo "Candance": também escrito Candace, sem o " $\mathrm{n}$ " depois do "a" e antes do "c".
} 
matriarcado em Cuxe $^{11}$ é um objeto interessantíssimo e oferece possibilidades pedagógicas formidáveis no que se refere às questões de gênero e política. No entanto, isso é tudo o que temos nesse sentido. Após as duas linhas supracitadas, observamos uma imagem com as ruínas das Pirâmides de Meroé, na região da Núbia. Mais uma vez, uma imagem é utilizada sem estar diretamente vinculada ao texto apresentado. Aqui, o leitor há de supor as semelhanças entre Cuxe e Egito, comparando as estruturas piramidais dos templos. Agora, sabemos que as pirâmides não eram uma exclusividade do Egito, e que outros povos também foram capazes desses grandiosos feitos arquitetônicos. No entanto, isto é tudo que produziam os cuxitas? Não produziam arte? Não moldavam esculturas? Não desenvolveram recursos de escrita? Não eram referência em outros aspectos da produção cultural ? $^{12}$

Chegando ao final da atividade, em menos de três linhas, os propositores das Trilhas fazem mais um recorte de Munanga, para tratar agora do Império de Axum: "Desenvolveu-se no território mais ou menos correspondente à Etiópia. Uma de suas características foi o cristianismo. [...] Não há dúvida sobre as influências da civilização egípcia, como mostram os obeliscos e mosteiros da capital Axum" (MUNANGA, 2004, apud: SÃO PAULO, 2020b, p. 124). Que espécie de inferência esperamos de nosso aluno após esta leitura? Axum ficou representada como uma civilização definida pelo cristianismo com influência egípcia na construção de templos cristãos. A imagem que viria como apoio exibe um templo cristão axumita, de arquitetura em formato de cruz. Será que para o aluno, o intercâmbio entre Axum e Egito ficou nítido? Além disso, cabe repor aqui as mesmas perguntas que fizemos em relação aos cuxitas, indicadas acima. E por que também não falar dos outros destaques em Axum: a coleta de marfim, o comércio, a agricultura, as técnicas de escrita e cunhagem de moedas...? ${ }^{13}$

Eis que chegamos à questão da atividade. Diz o enunciado: "Os trechos que lemos e as imagens que observamos mostram um pouco da cultura dos povos africanos da Antiguidade. Descreva o que você achou mais interessante sobre cada uma das civilizações da Antiguidade Africana." (SÃO PAULO, 2020b, p. 125).

O enunciado, portanto, não é muito desafiador, mas, abre a possibilidade para o aluno refletir sobre elementos que lhe chamaram a atenção nas culturas em evidência. O grande problema aqui, não está exatamente no enunciado, mas, no foco que fora dado ao Egito, enquanto se relega o Reino de Cuxe e o

\footnotetext{
11 Também escrito "Kush".

12 Para mais elementos sobre a civilização cuxita, Cf.: SILVÉRIO, 2013, pp. 199-213.

${ }^{13}$ A discussão de tais aspectos pode ser encontrada em: SILVÉRIO, 2013, pp. 216-229.
} 
Império de Axum à posições coadjuvantes no debate estabelecido. Isso, com certeza, prejudica a execução do exercício, uma vez que há, quantitativamente e qualitativamente mais elementos sobre o Egito, do que sobre Cuxe e Axum.

Os propositores das Trilhas optaram por supervalorizar o Egito e introduzir de maneira parca Cuxe e Axum. É evidente que todo projeto editorial pedagógico deve atentar-se à questão de espaço. Contudo, se este é um fato notório, por que não dividir igualmente o espaço entre as civilizações selecionadas para compor a atividade, ou ainda, por que não desmembrar a atividade em três, para que todas sejam devidamente elucidadas? Assim, é possível observar certa desigualdade geográfico-pedagógica entre os temas elencados. Parece que o que está na África subsaariana é menos digno de espaço e memória do que o que está ao norte do Saara. E se isso ocorre, há um problema de responsabilidade na elaboração da atividade. ${ }^{14}$ Em uma sociedade colorista ${ }^{15}$, é salutar garantir o devido espaço da memória negra, do tom mais escuro.

\section{Análise da atividade "A resistência negra no regime es- cravista: Quilombos"}

Com o início da pandemia, que não estava no planejamento de nenhuma instituição, novas formas de ensinar tiveram que ser criadas quase que "a toque de caixa" na tentativa de contemplar as necessidades de aprendizagem dos educandos no estudo remoto, o material apostilado foi uma destas tentativas.

Baseados na lei 11.645/08, analisaremos aqui a proposta de atividade 2 do caderno de Ciências Humanas do $7^{\circ}$ ano do ensino fundamental, do material Trilhas de aprendizagens. A atividade tem como título: "A resistência negra no regime escravista: Quilombos".

A temática de "quilombos" está de acordo com o currículo da cidade para o ano/ciclo mencionado, dentro dos Objetos de Conhecimento, o tópico "Formas de resistência à escravização e à dominação" e o Objetivo de Aprendizagem "(EF07H07) Conhecer e refletir sobre a diversidade das populações africanas trazidas ao Brasil e a disseminação de suas referências culturais na vida brasileira” (SÃO PAULO, 2019, p.90) é possível afirmar que o tema proposto contempla a proposta curricular.

\footnotetext{
${ }^{14}$ Cf. DE BAETS, 2013. Neste ensaio, De Baets discute como o uso abusivo e irresponsável da História pode trazer conseqüências sociais nocivas, tais como, a perpetuação de preconceitos, que nos levam a toda sorte de violências (simbólicas, psicológicas e, no limite, físicas).

15 "De uma maneira simplificada, o termo quer dizer que, quanto mais pigmentada uma pessoa, mais exclusão e discriminação essa pessoa irá sofrer". Cf. DJOKIC, 2015.
} 
Logo no início da atividade, constatamos a presença de uma provocação para iniciar a reflexão: a suposta aceitação passiva da escravização - "Durante muitos anos, no Brasil acreditou-se que o africano escravizado sofreu de maneira passiva todos os maus tratos praticados pelos senhores. Essa crença interferiu e interfere, ainda hoje, no imaginário da sociedade brasileira, a respeito de negros e negros brasileiros" (SÃO PAULO, 2020c, p.107). Compreende-se então que a atividade nos levará a um caminho de indagações e questionamentos acerca de tal imaginário social. Porém, nesta mesma provocação, ao invés de citar as etnias africanas que aqui chegaram de forma forçada, é usado no singular "o africano" escravizado. Tratar assim os diversos povos que aqui chegaram forçadamente, induz a um pensamento homogeneizado, como se todas as pessoas em África pertencessem a um mesmo padrão social, linguístico e cultural. Tal perspectiva invisibiliza identidades e características, tratando uma imensidão de culturas, costumes, línguas, religiões e fenótipos de forma única e sem complexidade e diversidade, oferecendo certo perigo na construção de identidade da população negra brasileira, que ao se erigir, não se vê pertencente e nem se identifica a nenhum grupo social ancestral.

Em nossa leitura, a atividade inicia com uma boa problemática: o fato de se acreditar por muitos anos em uma aceitação pacífica da escravização, gerando problemas no imaginário da população brasileira a respeito de negros e negras. Porém, não se define quais seriam tais problemas e tais imaginários, a questão fica subentendida e pouco desenvolvida (SÃO PAULO, 2020c, p.197).

Em seguida, é utilizado um trecho do livro "Para entender o negro no Brasil hoje: história, realidades, problemas e caminhos" de Kabengele Munanga, que citamos abaixo:

Costuma-se pensar o quilombo como 'refúgio de negros escravos fugitivos’. Apesar de terem se passado centenas de anos, essa ideia distorcida de quilombo ainda permanece entre nós. Insistir em tal conceito significa negar ou tornar invisível o verdadeiro sentido e história dos quilombos. [...] os quilombos brasileiros podem ser considerados como uma inspiração africana, reconstruída pelos escravizados para se opor a uma estrutura escravocrata, pela implantação de uma outra forma de vida.(...) neste sentido, o quilombo não significa refúgio de escravos fugidos. Tratava-se de uma reunião fraterna e livre, com laços de solidariedade e convivência, resultante do esforço de negros escravizados de resgatar sua liberdade e dignidade por meio da fuga do cativeiro e da organização de uma sociedade livre. Os quilombolas eram homens e mulheres que se recusavam a viver sob o regime da escravidão e desenvolviam ações de luta e 
rebeldia contra esse sistema (MUNANGA, 2004, apud: SÃO PAULO, 2020c, p. 107.).

A citação acima também pode ser lida no material Trilhas e as ideias desenvolvidas por Munanga possibilitam uma série de reflexões, desdobramentos e provocações. Ele aponta para a leitura equivocada do quilombo como um espaço apenas de refúgio de fugitivos, e que apesar do tempo e espaço, tal perspectiva permanece no imaginário social. $\mathrm{O}$ autor aponta para a necessidade de se compreender o quilombo como um espaço de resistência, valorização e manutenção da cultura africana. Era onde as pessoas escravizadas se organizavam e resistiam ao sistema escravocrata vigente, portanto, quilombo, para o autor, possui outros significados como possibilidade de liberdade e de constituição de outra forma de vida.

Como apontamos, apesar de todas essas provocações possíveis, ao chegar de fato à proposta de atividade, nos deparamos com a seguinte pergunta: "Qual o papel que os quilombos tiveram na vida dos africanos escravizados durante o regime escravista no Brasil?” (SÃO PAULO, 2020c, p.107, o grifo é nosso) A mesma está acompanhada logo abaixo de um espaço livre de cinco linhas para as possíveis respostas dos educandos. Ao ler a questão, é possível observar que apesar da tentativa, a questão está genérica e pouco provocativa, deixando a cargo dos educandos uma série de problematizações e conclusões, que sem um apoio pedagógico e melhor explicação no corpo do texto, dificilmente será possível o desenvolvimento de uma resposta elaborada e consistente. Uma segunda questão é que a pergunta ignora as comunidades quilombolas ainda existentes em todo o território brasileiro, abrindo mão de se estabelecer um diálogo entre passado e presente, levando a uma possível compreensão de que quilombos se restringem ao período escravocrata no Brasil.

Ao observar e analisar o material, compreendemos que apesar de passado alguns anos da promulgação da lei 10.639/03 e posteriormente da 11.645/08 ainda há problemas de ordem metodológica e teórica ao propor questões acerca da cultura afro-brasileira, e tais problemas, quando não compreendidos e sanados, colaboram para a manutenção do olhar estereotipado que a atividade proposta tem intenção de questionar e criticar. 


\title{
Análise da atividade "Como o continente africano enfren- tará a pandemia do coronavírus?"
}

\begin{abstract}
Podemos falar dos estereótipos das grandes midias: pobreza, fome, guerra, safaris. Mas as generalizações não param por ai [...] é sempre dado maior destaque aos elementos negativos, como guerras civis, choques étnicos, miséria, Aids. São elementos presentes em parte do continente, mas que devem ser contextualizados [...]. É errado dizer que esses elementos estão presentes em grande parte do continente. Não estão. Estão apenas em alguns pontos apenas. São pequenos focos em um continente de $1 \mathrm{bi}$ thão de pessoas e 54 países. Muitos desses são enormes e o que acontece em uma região do país, muitas vezes, não é vivida por outra. ${ }^{16}$
\end{abstract}

"Como o continente africano enfrentará a pandemia do coronavírus?" é a pergunta geradora da atividade para o $8^{\circ}$ ano das Trilhas de aprendizagens que analisaremos agora. A epígrafe acima nos ajudou na construção de alguns apontamentos sobre a referida atividade. Marcada por estereótipos propagados nas grandes mídias, como apontou Flora Pereira.

A referida atividade procurou marcar a presença da "África" no material didático a partir de uma reportagem publicada em 21 de março de 2020 no Jornal Nexo ${ }^{17}$. A partir da compilação de informações presentes na reportagem, foi produzido um texto com o objetivo de informar professoras, professores e as/os estudantes do $8^{\circ}$ ano do ensino fundamental, como estava a pandemia da COVID-19 no continente africano.

O título da matéria foi aproveitado em sua totalidade no texto adaptado, sendo acrescentado pela equipe que produziu o material um ponto de interrogação: "Qual a situação do coronavírus no continente africano?" (SÃO PAULO, 2020d, p.128).

Para ilustrar o texto original, publicado pelo Jornal Nexo, havia uma imagem fotográfica, feita em 19 de março de 2020, com a seguinte legenda: "Estudantes aprendem a lavar as mãos em uma escola na Nigéria". Na imagem, vemos 5 estudantes (inferimos que são quatro meninas e um menino). Três des-

\footnotetext{
${ }^{16}$ PORTAL CARTA CAPITAL, 2017. Trecho da entrevista com Flora Pereira. Pereira é idealizadora e diretora do Projeto "Afreaka: África sem estereótipos", com o intuito de "descortinar o continente para o Brasil, fugindo dos estereótipos negativos como fome, pobreza e passividade". O projeto resultou em uma publicação que foi distribuída gratuitamente em 1800 escolas públicas, em 240 cidades do Estado de São Paulo. Cf.:Disponível em: < $\underline{\text { http://www.afreaka.com.br/ }}$ >. Acesso em: 16 out. 2020.

${ }^{17}$ Disponível em: $<$ https://www.nexojornal.com.br/expresso/2020/03/21/Qual-a-situação-docoronavírus-no-continente-africano $>$. Acesso em: 16 out. 2020.
} 
ses estudantes estão com as mãos embaixo de uma torneira acoplada a um balde/caixa d'água grande, com tampa, ambos na cor azul, apoiado em uma superfície de cimento. Ao lado do balde/caixa d'água está uma garrafa com álcool em gel. Complexa a legenda, não acham? Parece indicar que estudantes não lavavam ou não sabiam lavar as mãos antes da pandemia. Sigamos!

No texto adaptado da matéria, a equipe da SME-SP, optou também por utilizar uma imagem como ilustração. A foto na versão do material Trilhas ofereceu aos profissionais do ensino e estudantes paulistanos, outra imagem fotográfica, sem legenda. A fonte: "Wikimedia Commons" (um portal de imagens que nem sempre oferece informações completas sobre seus arquivos). Inferimos que sejam três meninos lavando as mãos em uma torneira, sendo a água da lavagem aparada por um balde. Podemos ver mais dos corpos dos três, sendo que dois deles olham diretamente para a câmera. O terceiro, o percebemos de perfil. A imagem é incompleta para uma atividade escolar e mais ainda para uma publicação. Não tem legenda. Não sabemos quem são esses meninos e em qual parte do continente africano composto por 54 países eles estão.

Nilma Bentes (ALBERTI; PEREIRA, 2007, p.433), ao afirmar que a Lei 10.639/03 é uma conquista, revela que um dos desafios da prática da lei está no nosso desconhecimento sobre a África. Para ela, "até hoje não sabemos de que África estamos falando. Já que não existe uma África, existem muitas". Essa preocupação a acompanhava de tal maneira que um dia ao encontrar com o Professor Kabengele Munanga, perguntou a ele: "Mas de qual África a gente vai falar? Porque são muitas Áfricas, não é? São mais de duas mil línguas, pode imaginar...?”. Se tomarmos essa atividade e a fonte que a gerou como referências e as lermos a partir das preocupações de Nilma Bentes, podemos dizer que desconhecemos o continente africano e toda sua potência. Pode ser até que tenhamos memorizado algumas informações, mas, não entendemos do que se trata quando mencionamos a palavra "África”. Precisamos pensar em 54 países, com mais de duas mil línguas originárias, cosmologias, epistemologias diferentes, só como preâmbulo.

O que nos restou foram mais perguntas: Por que nos preocupamos em pensar a pandemia no continente africano? É ótimo conhecermos histórias e culturas de diferentes povos e nações, ainda mais quando temos uma relação uterina com esses povos e nações. Mas, é com essa espécie de abordagem que avançaremos nesse sentido?

É fato que não temos acesso, pelo menos, não através das grandes mídias, a uma quantidade expressiva de informações sobre o continente africano na Contemporaneidade, de modo não estigmatizado. Mas, uma vez que não te- 
mos esses meios e havia uma pressa em produzir um material didático para o ensino e aprendizagem remota em razão da pandemia, por que não nos preocupávamos em como a pandemia seria enfrentada no Brasil levando em consideração nossa diversidade de raça, classe e gênero? Ou ainda, uma vez que fazíamos questão de saber como a pandemia estava atingindo o continente africano, tão importante para a história e cultura brasileira, porque não optamos por buscar fontes que nos informassem da agência dos povos africanos? Sobre como estavam enfrentando a pandemia... ${ }^{18}$ Quais medidas protetivas os governos estavam tomando para evitar a propagação do vírus nos diferentes países (seria possível fazer uma seleção, por exemplo, por países que têm o português como uma das línguas falada entre a população) do continente africano, por exemplo?

Por que trazer uma abordagem sobre o continente africano a partir do tema da doença em meio a uma crise sanitária planetária? Como pontuou Flora Pereira no texto de epígrafe, essa é uma visão estereotipada, produzida e divulgada pela mídia. A atividade causa ainda mais incômodo e torna-se ainda mais inapropriada quando consideramos que o público alvo formado por professoras, professores, estudantes e suas famílias, têm, em grande medida, lastro em territórios periféricos, constituídos significativamente por afrodescendentes (SANTIAGO, 2015). ${ }^{19}$

Perplexos diante do fato, outra pergunta sintomática nos contagia: Qual seria a contribuição dessa abordagem para a formação de estudantes da educação básica das periferias da cidade de São Paulo?

O movimento de olhar com atenção a atividade, inicialmente motivado por nossa indignação quanto ao fato de esta ter sido a última atividade na unidade de Ciências Humanas, seguido da constatação da pressa com que esse material foi produzido (20/03/20 a 13/04/20), sem a consulta dos professores da rede e marinado no calor do momento, ativou como primeiro apontamento a já conhecida "preocupação com a desgraça e pobreza do continente africano", que só reafirma uma visão estereotipada e preconceituosa sobre o continente de origem da humanidade.

Helio Schwartsman, recordando a frase dita por Albert Einstein, "Triste época! É mais fácil desintegrar um átomo do que um preconceito”, disse que Einstein estava quase certo, porque "quebrar um estereótipo é tão ou mais difícil que fragmentar um átomo porque o homem interpreta o mundo através de

\footnotetext{
${ }^{18}$ A esse propósito, Cf. o canal FATELIKU (no Youtube), Por que falar sobre pandemia no continente africano? Políticas e resistências.

${ }^{19}$ Nesta reportagem há um mapa da distribuição da população negra (pretos e pardos) na cidade de São Paulo por subprefeitura.
} 
categorias, que são só um nome neutro para preconceito". Acrescenta que "estereótipos são fontes das piores chagas, como racismo, sexismo e toda forma de intolerância". Então em que Einstein não acertou? Na visão de Schwartsman “o problema não é usar preconceitos para interpretar o mundo, mas o fato de muitos de nós nos recusarmos a abandoná-los mesmo quando desmentido por evidências e contrários a imperativos morais" (SCHWARTSMAN, 2007. In: SÃO PAULO, 2010, p.95).

Quais elementos levaram a equipe técnica da SME-SP a incorrer nessa leitura estereotipada? Partimos do pressuposto de que são profissionais bem preparados, como afirmou a professora e secretária adjunta de educação do município de São Paulo, Minea Paschoaleto Frateli, quando questionada recentemente ${ }^{20}$. E por serem bem preparados poderiam ter feito um levantamento prévio dos documentos referenciais produzidos neste século pela própria SMESP. Falamos de documentos ${ }^{21}$ construídos em diálogo direto com a Lei de Diretrizes e Bases da Educação Nacional (LDB), e com os dispositivos da Lei Federal 10.639/03 e da Lei Federal 11.645/08, que passaram a garantir o ensino de História e cultura africana e afrobrasileira e o ensino de História e cultura indígena no currículo das instituições de ensino e pesquisa em todo o território nacional, da educação infantil ao ensino superior ${ }^{22}$.

\section{Considerações Finais}

Feitas nossas reflexões, resultantes de minuciosa análise, dois pontos ficam em destaque: a pressa e a falta de diálogo dos propositores das Trilhas de aprendizagens com os profissionais inseridos em grupos de pesquisa, movimentos sociais e, até mesmo, com as professoras e professores da rede. Existe uma tentativa de dialogar com o ensino de História e cultura africana e afro-brasileira, porém, na prática, tal diálogo não foi desenvolvido com as diversas frentes que estão dentro deste debate. Considerando todas as referências que alicerçam a discussão sobre o recorte analisado, a qualidade do material ficou prejudicada.

É importante salientar que, quando falamos em pressa, temos em mente o período estabelecido para a produção das Trilhas de aprendiragem: de 20 de

\footnotetext{
${ }^{20}$ FRATELI, Minea Paschoaleto. As politicas educacionais no cenário de Covid-19. Curso de extensão universitária "Politicas Educacionais em Tempos de (pós)Covid-19: Perspectivas Crítico-esperançosas", realizado pela Escola do Parlamento da Câmara Municipal de São Paulo em parceria com a Faculdade de Educação da Universidade de São Paulo.

${ }^{21}$ Cf. SÃO PAULO, 2008; e Idem, 2010, por exemplo.

${ }^{22}$ Cf. OLIVEIRA, 2018.
} 
março à 13 de abril de 2020, ou seja, o material fora elaborado em menos de um mês ${ }^{23}$. Esse período marca o recesso escolar concedido aos estudantes e aos profissionais da rede enquadrada, coincidindo com o início do período de "quarentena” em São Paulo. No dia 13 de abril, fora anunciado o material apostilado. Os educadores não receberam um manual para o professor, como é costumeiro no trabalho com livros didáticos (é fundamental que haja transparência nas intenções pedagógicas dos propositores do material - objetivos, expectativas, metodologia sugerida). O material deveria ter sido enviado pelo serviço de correio às casas dos estudantes, porém, até o final do mês de junho (mais de dois meses depois do anúncio do material), muitos estudantes ainda não tinham recebido o material. Para além dos problemas relacionados à natureza pedagógica das Trilhas, sua distribuição contou com sérios problemas de logística.

Essa pressa e a falta de diálogo redobram o trabalho das professoras e professores, uma vez que eles se encontram obrigados pelo dever ético e legal a revisar e problematizar possíveis inconsistências e incoerências no material que lhe é oferecido, para desenvolver o trabalho pedagógico com suas turmas. A pressa é contraproducente.

Ao fim e ao cabo, é de se supor que os problemas relacionados à produção das Trilhas não afetaram apenas o ensino de História. No entanto, ao que nos cabe aqui, é necessário dizer que toda vez que abordamos de forma irresponsável o estudo da História da África e do negro no Brasil, tal como, as relações étnico-raciais, seguimos com a manutenção de preconceitos, estereótipos e estruturas sociais que hierarquizam grupos sociais, tais como, o racismo.

\section{Referências}

ALBERTI, Verena; PEREIRA, Amilcar Araujo. Histórias do movimento negro no Brasil: depoimentos ao CPDOC. Rio de Janeiro: Pallas; CPDOC-FGV. 2007.

AMARAL, Viviani Patrícia Pimenta. Autorretrato como construção da identidade: uma ação educativa em artes visuais para o ensino fundamental. 2018. 97 f. Dissertação (Mestrado Profissional em Artes) - Universidade Federal de Uberlândia, Uberlândia, 2018.

\footnotetext{
${ }^{23}$ É razoável pensar que, seria difícil o material ter sido concebido muito antes disso, pois, até o final da primeira quinzena do mês de março, as aulas seguiam normalmente na rede em questão.
} 
BRASIL. Lei $\mathbf{n}^{\circ}$ 10.639, de 9 de janeiro de 2003.

Lei $\mathbf{n}^{\mathbf{0}}$ 11.645, de 10 marco de 2008.

Diretrizes curriculares nacionais para a educação das relações étnico-raciais e para o ensino de História e cultura afro-brasileira e africana. Brasília: MEC, 2004.

DE BAETS, Antoon. Uma teoria do abuso da História. In: Revista brasileira de História. São Paulo, v. 33, n. 65, p. 17-60, 2013.

GONÇALVES, Luiz Alberto Oliveira; SILVA, Petronilha Beatriz Gonçalves e. Movimento negro e educação. Revista brasileira de educação, Set/Out/ Nov/Dez, n.15, 2000 (s.l.).

MUNANGA, Kabengele. Para entender o negro no Brasil hoje: história, realidades, problemas e caminhos. São Paulo: Global, 2004.

OLIVEIRA, Rosenilton Silva de. Educação para Diversidade Racial no Contexto Brasileiro: O contexto das Leis 10639/03 e 11645/08. Argumentos. v. 15, n.1, jan./jun. 2018. ISSN: 2527- 2551.

RAUEN, Roselene Maria; MOMOLI, Daniel Bruno. Imagens de si: o autorretrato como prática de construção da identidade. Revista Educação, Artes e Inclusão. Florianópolis, v. 11, n. 1, p. 51-73, 2015.

RIBEIRO, Djamila. O que é lugar de fala? Belo Horizonte: Letramento, 2017.

SÃO PAULO (Cidade). Caderno de Orientações Didáticas: Educação Etnicorracial - Ciclo I. São Paulo: SME / DOT, 2010.

Currículo da cidade: Ensino Fundamental: componente curricular: História. 2.ed. São Paulo: SME / COPED, 2019.

Orientações Curriculares: expectativas de aprendizagens para a educação étnico-racial na educação infantil, ensino fundamental e médio. São Paulo: SME/DOT, 2008.

Orientações didáticas do currículo da cidade: História. 2.ed. São Paulo: SME / COPED, 2019.

.Trilhas de aprendizagem ( $5^{\mathbf{o}}$ ano). São Paulo: COPED/SME, 2020.

. Trilhas de aprendizagem ( $6^{\circ}$ ano). São Paulo: COPED/SME, 2020.

.Trilhas de aprendizagem ( $7^{\mathbf{o}}$ ano). São Paulo: COPED/SME, 2020. 
Trilhas de aprendizagem $\left(8^{\circ}\right.$ ano). São Paulo: COPED/SME,

2020.

SILVA, Andressa Carvalho da; OLIVEIRA, Paula Cristina Silva de. Ressignificação da identidade negra em uma escola no distrito de Sopa, Diamantina-MG. Olhares: Revista do Departamento de Educação da Unifesp. São Paulo, v. 3, n. 1, p. 258-279, 2015.

SILVÉRIO, Valter Roberto (editor); BARBOSA, Muryatan Santana; RINCON, Mariana Blanco; ROCHA, Maria Corina (autores). Síntese da coleção História Geral da África: Pré-história ao século XVI. Brasília: UNESCO, MEC, UFSCar, 2013.

\section{Referências na web:}

CANAL FATELIKU (no Youtube). Por que falar sobre pandemia no continente africano? Políticas e resistências (transmissão em 02/07/2020). Disponível em: < https://youtu.be/aSHEwR0pRsI > Acesso em: 25 out. 2020.

DJOKIC, Aline. Colorismo: o que é, como funciona. Artigo do portal Geledés. Publicado originalmente em 26/02/2015. Disponível em: < https://www.geledes.org.br/colorismo-o-que-e-como-funciona/>. Acesso em: 25 jul. 2020.

MOREIRA, Juliano. Dicionário Histórico-Biográfico das Ciências da Saúde no Brasil (1832-1930)(s.d.). Online. Disponível em: $<$ http://www.dichistoriasaude.coc.fiocruz.br>. Acesso em: 07 maio 2019.

PÁGINA ESCOLA DO PARLAMENTO NO FACEBOOK. Políticas Educacionais em tempos de (pós)Covid-19 (transmissão em 26/06/2020). Disponível em: < https://www.facebook.com/watch/live/? $\mathrm{v}=265438091382943 \& \mathrm{ref}=$ watch permalink $>$. Acesso em: 16 out. 2020.

PORTAL AFREAKA. Disponível em: < $\underline{\text { http://www.afreaka.com.br/>. Aces- }}$ so em: 16 out. 2020.

PORTAL CARTA CAPITAL, A África sem estereótipos. Entrevista de Flora Pereira à Carta na Escola. Publicada originalmente em 17/02/2017. Disponível em: < https://www.cartacapital.com.br/educacao/africa-sem-estereotipos/ $/>$. Acesso em: 16 out. 2020. 
PORTAL NEXO. Qual a situação do coronavírus no continente africano (21/03/2020). Disponível em: < https://www.nexojornal.com.br/expresso/ 2020/03/21/Qual-a-situação-do-coronavírus-no-continente-africano $>$. Acesso em: 16 out. 2020 .

SANTIAGO, Tatiane. Levantamento mostra distribuição da população negra em São Paulo. In: PORTAL CEERT. Matéria postada em 23/12/2015. Disponível em: $<$ https://ceert.org.br/noticias/dados-estatisticas/9503/levantamento-mostra-distribuicao-da-populacao-negra-em-sao-paulo $>$. Acesso em: 16 out. 2020. 